\title{
Geographies of Influence: A Citation Network Analysis of Higher Education 1972-2014
}

\begin{abstract}
This paper provides a citation network analysis of the publications of the journal Higher Education from 1972 to 2014 inclusive. This represents nearly the entire history of the journal. It analyses the most published authors and the most cited articles, as well as the most cited authors. This data includes the highest number of publications both by institution and country of origin. 2176 articles were taken from Web of Science ${ }^{\mathrm{TM}}$ as a source of primary data. These articles were found to have 68,009 references. Analysis was carried out using the Web of Science ${ }^{\mathrm{TM}}$ online analytics tool and Excel®. Gephi ${ }^{\mathrm{TM}}$, a data visualisation and manipulation software, was then used to provide visual representations of the associated citation networks. These representations were shown to constitute "terrains" of citations or "geographies of influence"-effectively bringing to bear empirical data in support of Macfarlane's higher education research "archipelago". Nationality biases were observed between US and UK/European/Australian higher education journals. Results indicate that the most published authors throughout the journal's history are Meyer, Kember, Richardson, Enders and Prosser. Confirming earlier studies on UK and Australian journals, the five most cited authors are Entwistle, Clark, Marton, Biggs and Ramsden. The single most cited article is Clark's 1983 Higher education system: academic organization in cross-national perspective. The top publication years for the journal were 2012, 2009 and 2011. Results from this paper shed light into the evolving concerns of the journal and its readership, and provide a demonstration of a powerful way of analysing citation data.
\end{abstract}

Keywords: citation analysis, higher education journal, network analysis, Gephi ${ }^{\mathrm{TM}}$, bibliometric analysis

\section{Introduction}

Based in Europe, published in the Netherlands, and recognised as one of the leading international journals in higher education studies, Higher Education will, in a few short years, celebrate its $50^{\text {th }}$ year. How will this half-century of continuous operation be marked?

One obvious way would be to assess the journal's impact and influence on scholarly practice. But how will this be done? The extent of the journal's readership clearly does not necessarily equate to impact, and citation metrics themselves are an ambiguous measure of real worth as noted elsewhere (Calma \& Davies, 2015). The number of times articles in Higher Education are cited by $H E$ authors-i.e., citations to authors published within $H E$ by other $H E$ authors - seems both parochial and narcissistic. A more objective measure is to look at the number of citations to $H E$ articles drawn from other higher education journals. However, this too is problematic. How can journals be fairly chosen for this purpose from the vast number of academic titles currently in play (298 journals at last count, according to Excellence in Research for Australia 2010 Ranked Journals List)? Selecting for this purpose only the journals that cite Higher Education is, of course, self-serving. Ignoring others can be seen as deliberate. Similarly, merely being cited by others simpliciter is not necessarily a good thing either-one needs to be cited for praiseworthy reasons. 
Aggregated "impact scores" can have their place as broad evidence of the worthiness of an academic title, but these scores may mean little to scholars when seeking to send their papers for publication in a journal. A natural question that scholars may ask themselves is not 'what is the impact score?' but 'who gets published?' in a given journal, and 'how often'? Aggregated metrics do not provide this data. The enterprise of citation analysis and citation metrics is early in its development and is a blunt instrument. It might be expected that impact scores tally reliably with the number of high-profile individual academics that publish in a journal; however, this has not, to our knowledge, been measured.

While flawed, analysis of citations within particular journals can be revealing in one important sense: it can shed light on key authors considered most worthy of being mentioned by other academics in the journal. While self-referential, this can be a measure of influence by proxy. If those authors also happen to be independently well-regarded, well-known, and widely published in the field (e.g., in other journals, or by general reputation), this augers well for a journal that claims to be 'recognised as the leading journal of higher education studies' ('About this journal', 2015). However, to be useful, data of this kind need to be assessed over a long time period, and be compared with longitudinal citation data from similar journals. In this paper we attempt this task.

This paper continues a program of scholarly investigation already embarked on with another major journal in the field, the UK-based Studies in Higher Education (Calma \& Davies, 2015). Our aim then - and now - is to assess the entire publication history of three or more of the major journals in the field based in different regions of the world, and comparing these data with evidence from the extant citation analysis literature. We do this using Gephi ${ }^{\mathrm{TM}}$, a visualisation tool used for assessing citation networks. One aim is to assess the extent to which the patterns of citations reflect national biases. Do the patterns of citations-i.e., the most published authors, and most cited articles-align in UK, US, European, and Australasian journals? Are there regional differences? Another aim is to determine which of the authors feature pre-eminently and which transcend geographic and national borders? More crucially, amongst the pre-eminent journals in the field, which is more influential? What are the "terrains of influence" among citation networks?

This paper adds to our previous work by assessing the citation networks obtained for the journal Higher Education using data drawn from nearly its entire publication history from 1972 to our arbitrary cut-off point of 2014.

\section{Literature Review}

The discipline of Higher Education has not been subject to many systematic citation analyses unlike other areas of study. See for example, psychology (Griggs \& Collisson, 2013); economics (Bodenhorn, 2003); social work (Klein \& Bloom, 1992; Thyer \& Bentley, 1986) radiology (Nightingale \& Marshall, 2012); medicine (Xian \& Madhavan, 2013). However, there are some studies that stand-out and should be noted.

Budd (1990) investigated the published material commonly cited in the higher education literature and the most frequently cited. Basing his analysis exclusively on US journals, he 
determined that Astin, Pascarella, Feldman, Centra and Cameron were the most commonly cited authors in the discipline of Higher Education. Budd and Magnuson (2010) followed-up this study two decades later and found some expected variation in the most cited authors (Astin, Pascarella, Tinto, Kuh, Cabrara). The predominance of US authors being cited in US journals, while not surprising, was noted.

Two years later, Kandlbinder (2012) attempted a narrowly focussed citation analysis of one higher education journal over time. He assessed the citations from 15 consecutive issues over a five-year period of the Australian journal Higher Education Research and Development (HERD) - (1982-1986), comparing this to 16 issues published in a second five-year tranche of the same journal (2008-2010). John Biggs was the most cited author with 29 citations appearing in the periods under investigation. Kandlbinder also found that the top-ranking authors were mainly based in Australia in the first sample, but this was not the case in the second, indicating a broadening of educational focus away from local parochial concerns, to more international concerns inclusive of a wider audience. Kandlbinder then compared three prominent journals (Higher Education, Studies in Higher Education, and Teaching in Higher Education) with HERD, noting that one author (Biggs) appeared in all four journals. He also noted that Marton, Entwistle and Ramsden appeared in three of the journals. Other highlycited authors - namely, Clark, Becher, Barnett, Boud, Slaughter, and Rowland-featured in one or other journal, but not all four. While noting a number of Australasian authors, Kandlbinder's study did not indicate a geographic bias of local authors over international authors.

Tight (2008) took a different approach, and attempted a synoptic, longitudinal study of several higher education journals over one year of publication. Using a corpus of 17 English language higher education journals published outside North America in the year 2000, he noted that Clark, Ramsden, Becher, Biggs and Boud occupied the top-five positions of 'most cited' authors. On his extended list of most cited authors (i.e., those outside of, and including the top-five) most of the academics were based in the UK, with a disproportionately large Australian-based contingent (Ramsden, Biggs, Boud, Prosser, Trigwell).

In 2014, Calma and Davies adopted the longitudinal approach undertaken by Tight. However, like Kandlbinder, we focussed on only one journal, Studies in Higher Education. This paper was, to our knowledge, one of the few analyses of the entire history of citations in a single higher education journal. Notable are the contributions of Ross (1992) and Huisman (2008) for analysing two decades of Higher Education and Higher Education Policy, respectively. There is also a dated study by Westbury; however, Westbury's study was for a 10-year period using only six years of available data (1972-78) for the Journal of Curriculum Studies (Westbury, 1980). Our analysis, by contrast, involved the entire 37-year citation history of SHE. It revealed surprising unanimity with Kandlbinder in the 'top-five' most cited authors (although not the order of pre-eminence), and considerable conformity with Tight's list. Like Kandlbinder, we found that Biggs, Ramsden, Marton, Becher and Entwistle featured as our top-five authors - three of which (Ramsden,Biggs and Becher) - also featured on Tight's list. This is summarised in Table 1 below. From our 2014 analysis, it appeared to be the case that whilst US journals predominately cited other US authors, UK and Australian journals had no 
such geographic bias. In a more recent article by Tight (2014), he confirmed that American authors feature almost exclusively in US-based journals and very few publish outside the US. We wanted to investigate this further with another northern hemisphere journal, this time based in Europe. Would this reveal a similar trend? Our answer to this question is presented in the following pages.

Table 1

US, UK and Australia top authors from five various analyses

\begin{tabular}{|c|c|c|c|c|c|}
\hline & \multicolumn{2}{|c|}{ US } & UK & \multicolumn{2}{c|}{ Australian } \\
\hline & $\begin{array}{c}\text { Budd } \\
(1990)\end{array}$ & $\begin{array}{c}\text { Budd and Magnuson } \\
(2010)\end{array}$ & $\begin{array}{c}\text { Tight } \\
(2008)\end{array}$ & $\begin{array}{c}\text { Kandlbinder } \\
(2012)\end{array}$ & $\begin{array}{c}\text { Calma and Davies } \\
(2015)\end{array}$ \\
\hline 1 & Astin & Astin & Clark & Biggs & Entwistle \\
\hline 2 & Pascarella & Pascarella & Ramsden & Marton & Marton \\
\hline 3 & Centra & Tinto & Becher & Entwistle & Ramsden \\
\hline 4 & Baldridge & Kuh & Biggs & Ramsden & Biggs \\
\hline 5 & Feldman & Cabrara & Boud & Becher & Becher \\
\hline
\end{tabular}

Before leaving the literature, another paper on citation analysis in higher education should be mentioned. Macfarlane has constructed a somewhat tongue-in-cheek citations map that he calls a 'higher education research archipelago' (Macfarlane, 2012). Drawn from experience, rather than hard data, he notes a division in 'policy' research and 'teaching and learning' research - each forming "islands" of scholarship that have little to do with each other. Between them a "sea of disjuncture" has formed, and various "reefs" associated with specialist areas such as "identity", "philosophy" and "professional development". Comparing this to the higher education landscape in the 1980s (when he commenced his career), he noted the rise in publications about student learning in the past twenty years in contrast to the previous scholarship on policy areas. He also noted that the professionalism of authors has changed, shifting from an amateur culture to that of academics from adjoining and foundational disciplines such as a sociology, politics, philosophy and psychology. Macfarlane also identifies a number of the key figures in higher education today as being from the US, UK and Australia (Biggs, Barnett, Clark, Trow, Slaughter, Becher, Boud, Boyer, Land, Brew, to name a few), with a number of notable exceptions, namely Germans (Habermas, von Humbolt, Tiechler), French academics (Bourdieu), and a Moroccan (Salmi) (Macfarlane, 2012). Macfarlane's "archipelago" is reproduced below: 


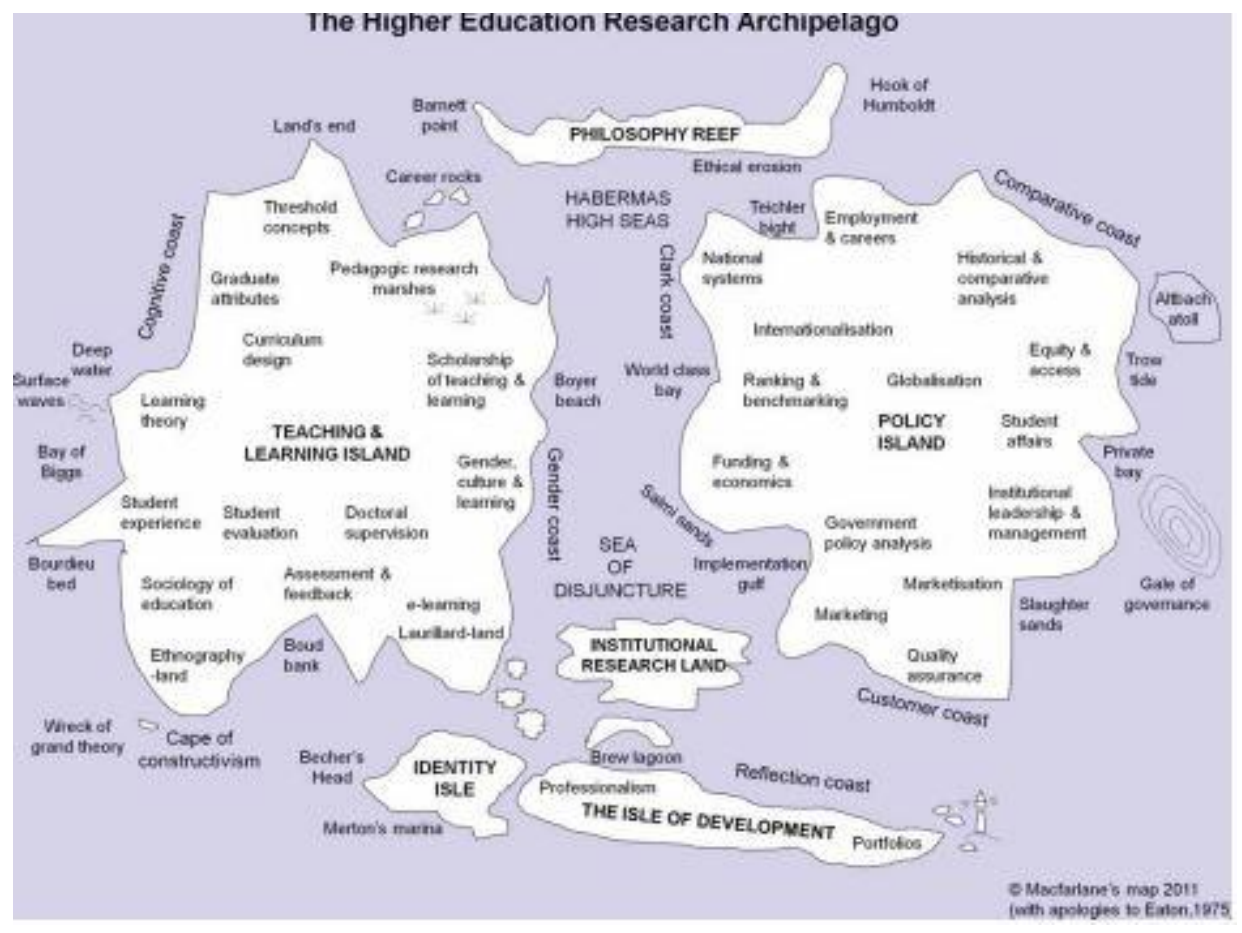

Figure 1. Macfarlane's “archipelago” (Macfarlane, 2012)

While interesting, Macfarlane's "archipelago" is based on no evidence. It is only an impressionistic sense of the discipline from the point of view of someone working in it. However, it is useful in thinking of higher education research as consisting of terrains of influence centring on the work of key figures.

A similar terrain of sorts was developed by Tight (2008) using citation data-although Tight discusses "clusters of relationships" rather than islands. Tight identifies a "Clark" cluster (reflecting interest in international and system-wide operational concerns of higher education), and a "Ramsden" cluster (indicative of teaching and learning concerns). While Tight does not adopt the metaphor of "islands", we can, following Macfarlane, use this term. These Clark/Ramsden islands of influence — according to Tight-were in addition to smaller, more isolated and independent, although loosely connected, "atolls" of importance (Barnett, Schon, Boud). Tight's schema is reproduced below with the addition of circles to show the islands of influence: 


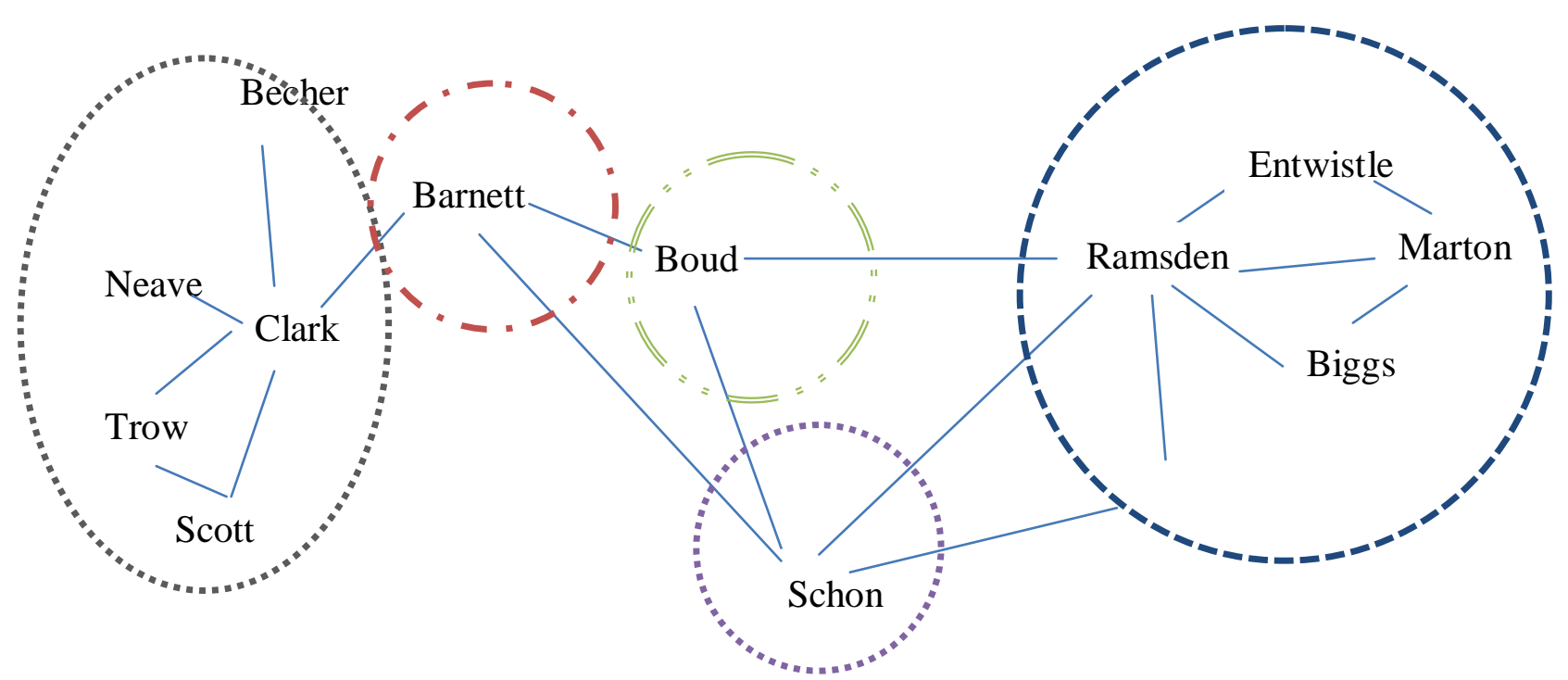

Figure 2. Citation Network Analysis (from Tight, 2008)

Can any sense be made of Macfarlane's archipelago, or Tight's clusters of relationships using citation data from the complete history of a key journal in the field? We look at this in the pages that follow.

\section{Method}

We should begin by explaining the concept of network analysis. In brief, network analysis is an investigation of interconnectedness of items in a given population as revealed by nodes and links between nodes. The thicker the lines between nodes, the most often it is represented in sample under consideration (i.e., the larger the number of instances) and the greater the evident "impact" of the item. In our case, the nodes represent authors, and the links are citations to an author and among/between author(s). This analysis technique is broadly similar to that conducted by Tight in his analysis of research communities, but in our case, this has been achieved for nearly an entire history of a particular journal $(H E)$, allowing for far greater analytical refinement.

There have been previous attempts to map citations in a similar way to that conducted by Tight, but by means of dedicated network analysis tools. This has occurred in a number of disciplines in the empirical sciences (Bornmann, Leydesdorff, \& Marx, 2007; Howard, 2011; Leydesdorff, 2007), but also in disciplines such as Philosophy (Healy, 2013), Archaeology (Brughmans, 2013), Educational Technology (Cho \& Park, 2012), Instructional Design (Anglin \& Towers, 1991), as well as Public Health, Medicine, Engineering, Economics, Human Research Management and Sports Psychology (Bruner, Erickson, Wilson, \& Côté, 2010; Moore, Shiell, Hawe, \& Haines, 2005) as well as lesser-known fields such as Coaching Science (Rangeon, Gilbert, \& Bruner, 2011).

What sense can be made of the citations data using network analysis in the discipline of higher education? The following sections describe the methods of data collection and analysis, limitations and assumptions in the present study. 


\section{Data preparation}

Web of Science ${ }^{\mathrm{TM}}$ was used to extract all Higher Education journal publications from 1972 through to 2014 on 8th January 2015. The extracted data was a CSV file (comma separated values) which was then tab-separated and exported to Excel® containing 2,167 articles (academic journal articles only). The file included information such as, amongst other things, author, title, keywords, abstract, number of references and publication year. This file was used to prepare all the necessary files for the subsequent analysis using Gephi ${ }^{\mathrm{TM}}$.

To derive an analysis of citations using Gephi ${ }^{\mathrm{TM}}$ two files are needed: a "nodes" file and a "edges" file. The following describes how these two files were prepared.

\section{Preparing the Nodes file}

A "Node" is a term used in Gephi ${ }^{\mathrm{TM}}$ to identify the record ID and label of a particular set of data. In our case, the nodes are the citing author(s)/article(s) and the cited author(s)/reference(s). Thus, the "Nodes" file uses IDs 1 to 2167 representing the 2,167 published articles from 1972-2014 and continues with IDs 2168 to 70176 representing the 68,009 cited references. Thus, 70,176 nodes were loaded onto Gephi ${ }^{\mathrm{TM}}$.

The Web of Science ${ }^{\mathrm{TM}}$ extracted data (i.e., "raw file") containing all metadata based on the search criteria (e.g. author, title, cited references, publication year, etc.) was extracted to gather the ID number and authors to prepare the Nodes file. For example, node "1, Zoller FA; Zimmerling E; Boutellier R" represents the most recent record in our data, representing ID=1 and Label=Zoller FA; Zimmerling E; Boutellier R (the article by these authors). All 70,176 ID and Label combinations were prepared in Excel and exported to Gephi ${ }^{\mathrm{TM}}$. The assignment of IDs is critical as these IDs will become the "source" and "target" IDs when preparing the "Edges" file.

Because the original Gephi ${ }^{\mathrm{TM}}$ file contained 70,176 nodes there were issues with running the Gephi ${ }^{\mathrm{TM}}$ application. It either crashed or took a considerably long time to run some analytics. As a result, another set of Gephi ${ }^{\mathrm{TM}}$ files was prepared focusing only on the top 10 cited authors and top 10 cited articles following analyses made in Excel®. This made running the data in $\mathrm{Gephi}^{\mathrm{TM}}$ more manageable.

\section{Preparing the Edges file}

An "Edge" shows the relationship between two nodes. For example, the article "Zoller FA; Zimmerling E; Boutellier R" (ID = 1) has 46 cited references (IDs 2168-2213). To construct an edge table for this ID, there will be 46 edges in total. Connections can be "directed" (if A cites to B, B might not cite A) or "undirected" (if A cites B, B cites A). In our data, a directed relationship is used. This process was repeated across all 2,167 articles using scripts and pivot tables. The undirected graph was also used at times simply to show connections and not relationships.

In total, there were 68,009 cited references from the 2,167 articles. This equated to an article citing an average of 31 references. Because the cited references would have their own target IDs, it was necessary to sort all references and give each author and each article a target ID (the target ID being the same for unique articles and authors). We were interested in both who 
cited who (i.e., most cited author) and who cited what (i.e., most cited article) in preparing the Edges file. Thus, two files were prepared: a file with target IDs for each unique article and a file with target IDs for each unique author. This is represented schematically as follows:

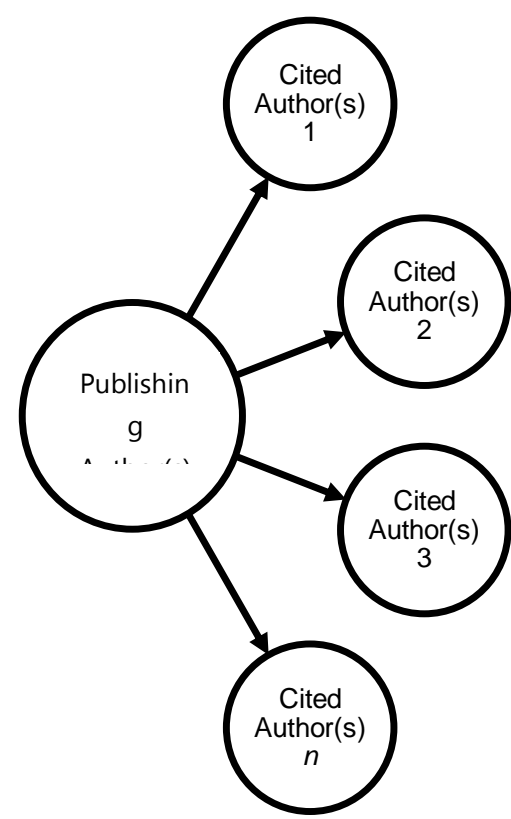

(a)

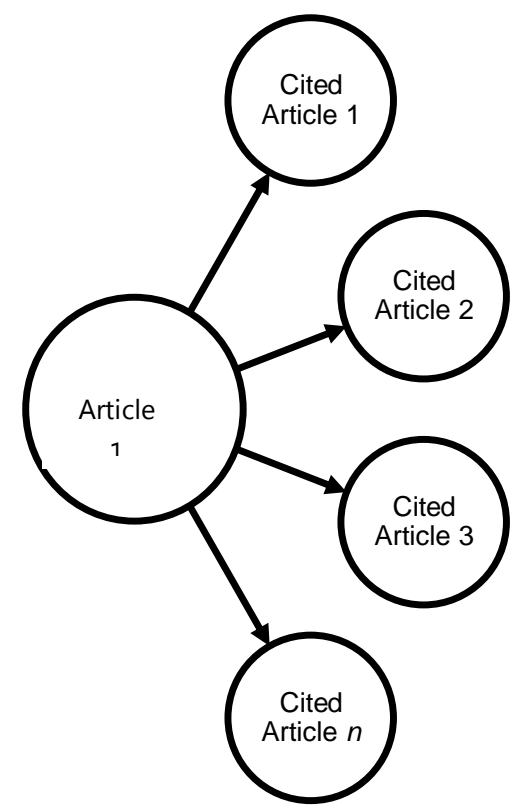

(b)

Figure. 2. A simplified diagram of nodes and edges for most cited author and most cited article.

For our study, the 68,009 IDs have been reduced to only include unique articles and unique authors (i.e. because one or more authors can cite the same reference). The result was 53,331 unique article IDs and 17,686 unique author IDs.

From the Excel® file, both the most cited author and most cited article can be easily seen (see Results section). The two Edges files were then exported to Gephi ${ }^{\mathrm{TM}}$ and both the Nodes and Edges files make up the Higher Education Gephi ${ }^{\mathrm{TM}}$ files.

Of the 68,009 cited references, there were 740 that were not properly formatted when their metadata were downloaded. They contained numbers, letters or other unusual characters (e.g. "1-Q") instead of the typical "Author, Year" format. 61 of those were with authors named "Anonymous" while another 612 were in the format "Year, Author" (e.g. "1974, Williams"). The remaining 67 cited references did not include an author or year but only the title of the article and other publication details. All 740 references were still given a target ID and included in the analysis.

\section{Method of analysis}

The analysis involved using both Excel ${ }^{\circledR}$ and Gephi ${ }^{\mathrm{TM}}$ with the former providing the data source for the latter. For the most cited author or article, Excel® was used for some of the analysis that only required a simple sum while Gephi ${ }^{\mathrm{TM}}$ was used for visualisation and 
manipulation to determine the size of the "node" for each author (the thicker the links, the higher the number of publications by that author). For the remaining analyses we used

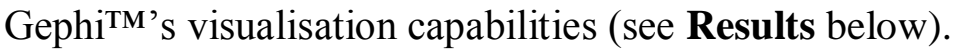

The analytics from Web of Science ${ }^{\mathrm{TM}}$ were also used for some of the analysis in this study. The online analytics resulted in identifying the top authors, top countries of publication, top organisations and top publication years. These results are also reported below.

\section{Results}

We discuss separately the results from Web of Science ${ }^{\mathrm{TM}}$ analytics, Excel® and Gephi ${ }^{\mathrm{TM}}$.

\section{Web of Science ${ }^{\mathrm{TM}}$ analytics results}

We begin our discussion by presenting the Web of Science ${ }^{\mathrm{TM}}$ analytics results.

Most published authors. From the table below (Table 2), we note that Meyer is the most published author in Higher Education, followed by Kember and Richardson, the three of them making up nearly $2 \%$ of all journal articles published in Higher Education. Note that the data is extremely reliable, with all articles containing author details.

Table 2

Top 20 authors

\begin{tabular}{llll}
\hline Rank & Author & Publications & \% of 2,167 \\
\hline 1 & Meyer JHF & 17 & 0.784 \\
2 & Kember D & 14 & 0.646 \\
3 & Richardson JTE & 12 & 0.554 \\
4 & Enders J & 11 & 0.508 \\
5 & Kyvik S & 10 & 0.461 \\
6 & Marginson S & 9 & 0.415 \\
& Prosser M & 9 & 0.415 \\
& Trigwell K & 9 & 0.415 \\
7 & Altbach PG & 8 & 0.369 \\
& Harman G & 8 & 0.369 \\
& Over R & 8 & 0.369 \\
& Teichler U & 8 & 0.369 \\
& Watkins D & 8 & 0.369 \\
8 & Lysons A & 7 & 0.323 \\
& Moses I & 7 & 0.323 \\
& Psacharopoulos G & 7 & 0.323 \\
& Slaughter S & 7 & 0.323 \\
& Schmidt HG & 7 & 0.323 \\
& Vermunt JD & 7 & 0.323 \\
& Westerheijden DF & 7 & 0.323 \\
\hline
\end{tabular}

Top publishing countries. The following also report the top countries articles are associated with (Table 3). Authors from the USA, Australia and England make up more than $50 \%$ of all published articles in Higher Education. A small proportion (13 or .6\%) of the articles do not 
contain data on country of origin. Given the size of the population ( 24 million), Australia would seem to have a disproportionate influence in terms of publication success in the journal.

Table 3

\begin{tabular}{llll} 
Top 20 countries & & \\
\hline No. & Country/Territory & Records & \% of 2,167 \\
\hline 1 & USA & 431 & 19.889 \\
2 & Australia & 358 & 16.521 \\
3 & England & 344 & 15.874 \\
4 & Canada & 126 & 5.814 \\
5 & Netherlands & 114 & 5.261 \\
6 & South Africa & 80 & 3.692 \\
7 & Israel & 70 & 3.230 \\
8 & Scotland & 56 & 2.584 \\
9 & Sweden & 52 & 2.400 \\
10 & Spain & 50 & 2.307 \\
11 & Peoples R China & 49 & 2.261 \\
12 & Finland & 48 & 2.215 \\
13 & Japan & 47 & 2.169 \\
14 & Germany & 43 & 1.984 \\
15 & Norway & 42 & 1.938 \\
16 & Italy & 27 & 1.246 \\
17 & France & 27 & 1.246 \\
18 & New Zealand & 25 & 1.154 \\
19 & Portugal & 24 & 1.108 \\
20 & Belgium & 24 & 1.108 \\
\hline
\end{tabular}

Top publishing institutions. Nearly $15 \%$ of all published articles come from the top 10 institutions across the UK, Australia, Netherlands, Africa and Hong Kong (Table 4). Again, it seems there is a disproportionate number of Australian institutions represented, comprising 50 percent of the top 10 institutions, and 50 percent of the top 20 (in bold).

Table 4

Top 20 institutions

\begin{tabular}{llll}
\hline & Institution & Records & \% of 2,2167 \\
No. & & & \\
\hline 1 & Open University & 45 & 2.077 \\
2 & University of & 44 & 2.030 \\
& Lancaster & & \\
3 & Monash University & 33 & 1.523 \\
4 & University of Sydney & 32 & 1.477 \\
5 & University of Twente & 30 & 1.384 \\
6 & University of & 30 & 1.384 \\
& Melbourne & & \\
7 & University of New & 27 & 1.246 \\
\hline
\end{tabular}




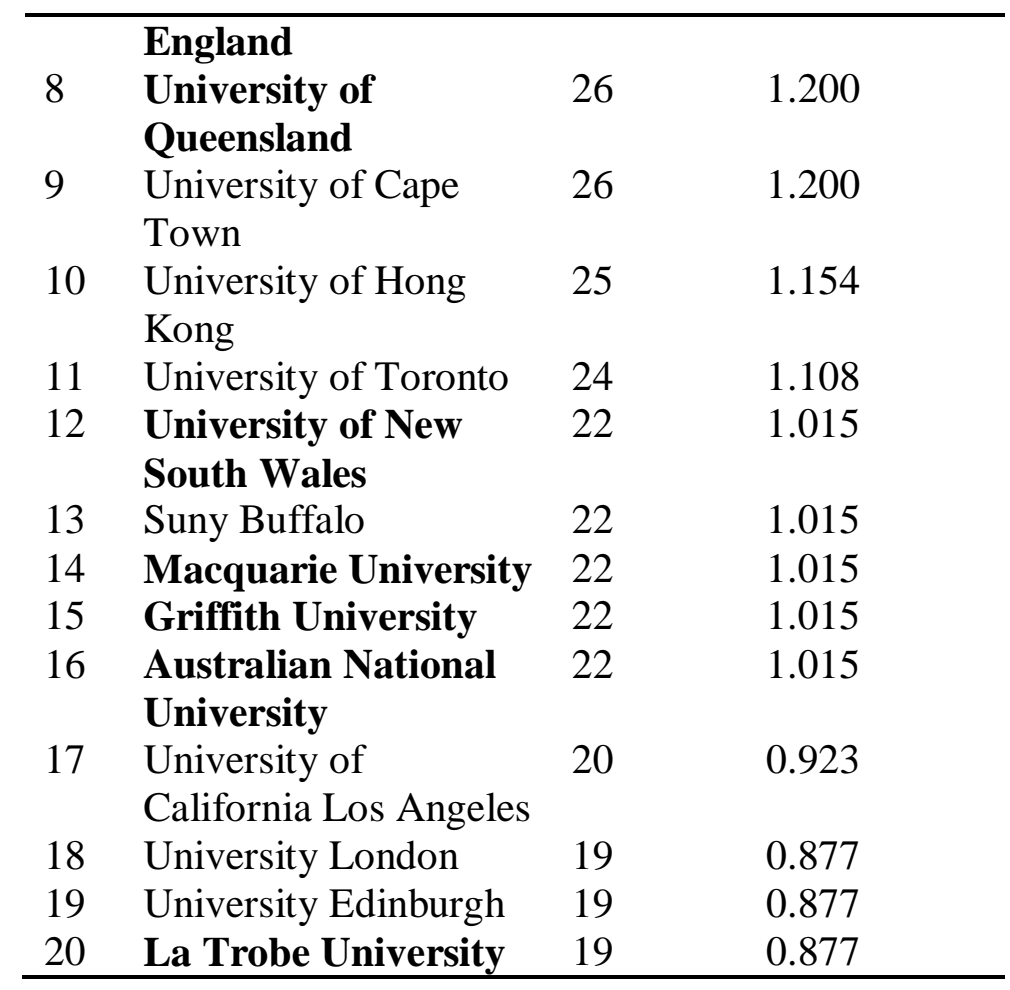

Top years of publication. Finally, the top publication years are reported below (Table 5). It can be seen that there was a spike in the number of publications from 2007, leaving 2012, 2009 and 2011 as the top three publication years with a combined total of 278 articles for that period. We note that these figures could be due to changes in submission and acceptance rates, special issues, number of volumes and issues.

Table 5

Top 20 publication years

\begin{tabular}{llll}
\hline No. & Year & $\begin{array}{l}\text { No. of } \\
\text { publications }\end{array}$ & \% of 2,167 \\
\hline 1 & 2012 & 96 & 4.430 \\
2 & 2009 & 93 & 4.292 \\
3 & 2011 & 89 & 4.107 \\
4 & 2013 & 88 & 4.061 \\
5 & 2010 & 84 & 3.876 \\
6 & 2008 & 83 & 3.830 \\
7 & 2007 & 80 & 3.692 \\
8 & 2014 & 79 & 3.646 \\
9 & 1973 & 57 & 2.630 \\
10 & 1994 & 56 & 2.584 \\
11 & 1992 & 55 & 2.538 \\
12 & 1991 & 55 & 2.538 \\
13 & 1993 & 54 & 2.492 \\
14 & 2006 & 53 & 2.446 \\
15 & 1990 & 52 & 2.400 \\
16 & 1995 & 50 & 2.307 \\
\hline
\end{tabular}




\begin{tabular}{llll}
\hline 17 & 1997 & 49 & 2.261 \\
18 & 2005 & 48 & 2.215 \\
19 & 2004 & 48 & 2.215 \\
20 & 2002 & 48 & 2.215 \\
\hline
\end{tabular}

Most cited articles. According to the Web of Science ${ }^{\mathrm{TM}}$ data, the most cited articles in the journal's history are given below (Table 6).

Table 6

Most cited article or reference

\begin{tabular}{lll}
\hline Rank & Article or Reference & Times cited \\
\hline 1 & $\begin{array}{l}\text { Biggs, J. (1995). Enhancing teaching through } \\
\text { constructive alignment. }\end{array}$ & 250 \\
2 & $\begin{array}{l}\text { Trigwell, K., Prosser, M. \& Waterhouse, F. (1999). } \\
\text { Relations between teachers' approaches to teaching } \\
\text { and students' approaches to learning. }\end{array}$ & 238 \\
3 & $\begin{array}{l}\text { Biggs, J. (1979). Individual differences in study } \\
\text { processes and the quality of learning outcomes. }\end{array}$ & 209 \\
4 & $\begin{array}{l}\text { Entwistle, N. \& Tait, H. (1990). Approaches to } \\
\text { learning, evaluation of teaching, and preferences for }\end{array}$ & 166 \\
& $\begin{array}{l}\text { contrasting academic environments. } \\
\text { Trigwell, K. \& Prosser, M. (1991). Improving the } \\
\text { quality of student learning - the influence of learning } \\
\text { context and student approaches to learning on }\end{array}$ & 162 \\
& $\begin{array}{l}\text { learning outcomes. } \\
\text { Vermunt, J.D. (1996). Metacognitive, cognitive and } \\
\text { affective aspects of learning styles and strategies: A }\end{array}$ & 155 \\
& $\begin{array}{l}\text { phenomenographic analysis. } \\
\text { Topping, K.J. (1996). The effectiveness of peer } \\
\text { tutoring in further and higher education: A typology } \\
\text { and review of the literature. }\end{array}$ & 145 \\
& $\begin{array}{l}\text { Entwistle, N., Hanley, M. \& Hounsell, D. (1979). } \\
\text { Identifying distinctive approaches to studying. } \\
\text { Robinson, R. (2004). Pathways to completion: } \\
\text { Patterns of progression through a university degree. } \\
\text { Samuelowicz, K., \& Bain, J.D. (1992). Conceptions } \\
\text { of teaching held by academic teachers. }\end{array}$ & 125 \\
\hline
\end{tabular}

\section{Excel ${ }^{\circledR}$ results}

From the Excel® spreadsheet, there are a number of analyses that can be made.

Most cited articles. First, an analysis of the most cited articles was made (Table 7). Burton Clark's Higher education system: academic organization in cross-national perspective remains the most cited reference in Higher Education journal (109 citations). Taking into account his other article (ranked 6), he would have a total of 167 citations to his name. Although Ference Marton and Roger Säljö's articles On qualitative differences in learning I: 
outcome and process and On qualitative differences in learning II: outcome and process were ranked second (103), they were supplanted by Becher if his two articles are combined (109). It can be reliably said that the two most influential articles in Higher Education were about the systems of higher education and disciplinary cultures.

Table 7

Top 10 most cited articles

\begin{tabular}{llll}
\hline No. & Publication year & $\begin{array}{l}\text { No. } \\
\text { citations }\end{array}$ & of $\%$ of 68,009 \\
\hline 1 & $\begin{array}{l}\text { Clark, B. R. (1983). Higher education } \\
\text { system: academic organization in cross- } \\
\text { national perspective. }\end{array}$ & 109 & .160 \\
& &
\end{tabular}

2 Marton, F. \& Säljö, R. (1976). On

103

qualitative differences in learning (I, II): outcome and process. British Journal of

Educational Psychology, v46.

3 Slaughter S. \& Leslie, L. (1997).

Academic capitalism: politics, policies and the entrepreneurial university.

$4 \quad$ Entwistle N. J. \& Ramsden, P. (1983).

Understanding student learning.

5 Gibbons, M., Limoges, C., Nowotny, H.,

Schwartzman, S., Scott, P. and Trow, M.

(1994). The new production of knowledge: the dynamics of science and research in contemporary societies.

entrepreneurial universities: organizational pathways of transformation.

Becher, T. (1989). Academic tribes and territories: intellectual enquiry and the cultures of disciplines.

8 Becher, T. and Trowler, P.

(2001). Academic tribes and territories: intellectual enquiry and the cultures of disciplines.

9 Prosser M. \& Trigwell, K. (1999).

Understanding learning and teaching: the experience in higher education. 
$10 \quad$ Biggs J. B. (1987). Student approaches to $45 \quad .066$

learning and studying.

Most cited authors. Although Clark tops the most cited publications in Higher Education, it is Noel Entwistle that has the most citations (Table 8), followed by Clark, Marton, Biggs and Ramsden who together occupy the position of top-five 'most cited' authors, representing $2.77 \%$ of all cited references.

Table 8

Top 10 most cited authors (as single or first author)

\begin{tabular}{llll}
\hline No. & Author & $\begin{array}{l}\text { No. } \\
\text { times } \\
\text { cited }\end{array}$ & of of 68,009 \\
\hline 1 & Entwistle, N. J. & 472 & .694 \\
2 & Clark B. R. & 396 & .582 \\
3 & Marton, F. & 391 & .575 \\
4 & Biggs, J. & 369 & .543 \\
5 & Ramsden, P. & 258 & .379 \\
6 & Becher, T. & 222 & .326 \\
7 & Slaughter, S. & 189 & .278 \\
8 & Prosser, M. & 117 & .172 \\
9 & Gibbons, M. & 107 & .157 \\
10 & DiMaggio, P.J. & 60 & .088 \\
\hline
\end{tabular}

Most published authors. Our study also showed Meyer, Kember and Richardson as the most published authors. This is identical to the analytics results from Web of Science ${ }^{\mathrm{TM}}$ given in Table 2. Table 9, however, distinguishes between those articles published solely or as first author and those co-authored. In our list we found more articles by Prosser when author and co-authors are combined, making him rank $4^{\text {th }}$ on our list compared to $6^{\text {th }}$ in Web of Science $^{\mathrm{TM}}$. Similarly, Watkins also moved up one rank in our analysis.

Table 9

Most published authors

\begin{tabular}{lllll}
\hline No. & Author & $\begin{array}{l}\text { As first } \\
\text { or single } \\
\text { author }\end{array}$ & As co-author & $\%$ of 2,167 \\
& & 11 & 6 & .784 \\
\hline 1 & Meyer JHF & 9 & 5 & .646 \\
2 & Kember D & 6 & 6 & .554 \\
3 & Richardson JTE & 7 & 4 & .508 \\
4 & Enders J & 2 & 9 & .508 \\
& Prosser M & 7 & 3 & .461 \\
5 & Kyvik S & 7 & 2 & .415 \\
6 & Trigwell K & 8 & 1 & .415 \\
& Marginson S & & & \\
\hline
\end{tabular}




\begin{tabular}{lllll}
\hline \multirow{2}{*}{7} & Watkins D & 6 & 3 & .415 \\
& Teichler U & 7 & 1 & .369 \\
& Altbach PG & 7 & 1 & .369 \\
Harman G & 7 & 1 & .369 \\
Over R & 6 & 2 & .369 \\
\hline
\end{tabular}

\section{Gephi $^{\mathrm{TM}}$ diagrams}

Our Gephi ${ }^{\mathrm{TM}}$ analysis allows for greater analytical refinement and visualisation of the data. It will be recalled that the citing author(s) and cited references are the "nodes" and the "edges". Together, these show which author cited another. In our analysis, each of the 2,167 nodes was connected to the 68,009 cited references. The original Gephiтм diagram for Higher Education shows 70,176 nodes and 68,009 edges. A preview of these connections would not be instructive as it is composed of a large web of connections shown as a ball of black text when the node labels feature in Gephi is turned on. Instead, Gephi' ${ }^{\mathrm{TM}}$ files were limited to providing a visual representation of only the 'most cited' articles and 'most cited' authors. These are displayed below.

\section{Most cited articles}

In Table 7 we have shown the top 10 'most cited' articles. To visualise the extent of connections of these 10 articles, a Gephi ${ }^{\mathrm{TM}}$ diagram is useful. Figures 3 and 4 below illustrate the top 10 authors in Gephi ${ }^{\mathrm{TM}}$, comprising 725 nodes and 715 edges. Figure 3 shows the top 10 cited articles. The darker the dot the more connections the article has (i.e. more authors have cited the article). To see this in more detail, we need to place the most cited paper in the centre of the diagram, with the remaining nine papers subordinate to this. Figure 4 illuminates this, showing Clark's 1983 article — the most highly cited in the journal's history - as the darkest dot at the centre of the diagram indicating the most number of edges. Each white circle represents the articles/authors that cited any of the top 10 authors.

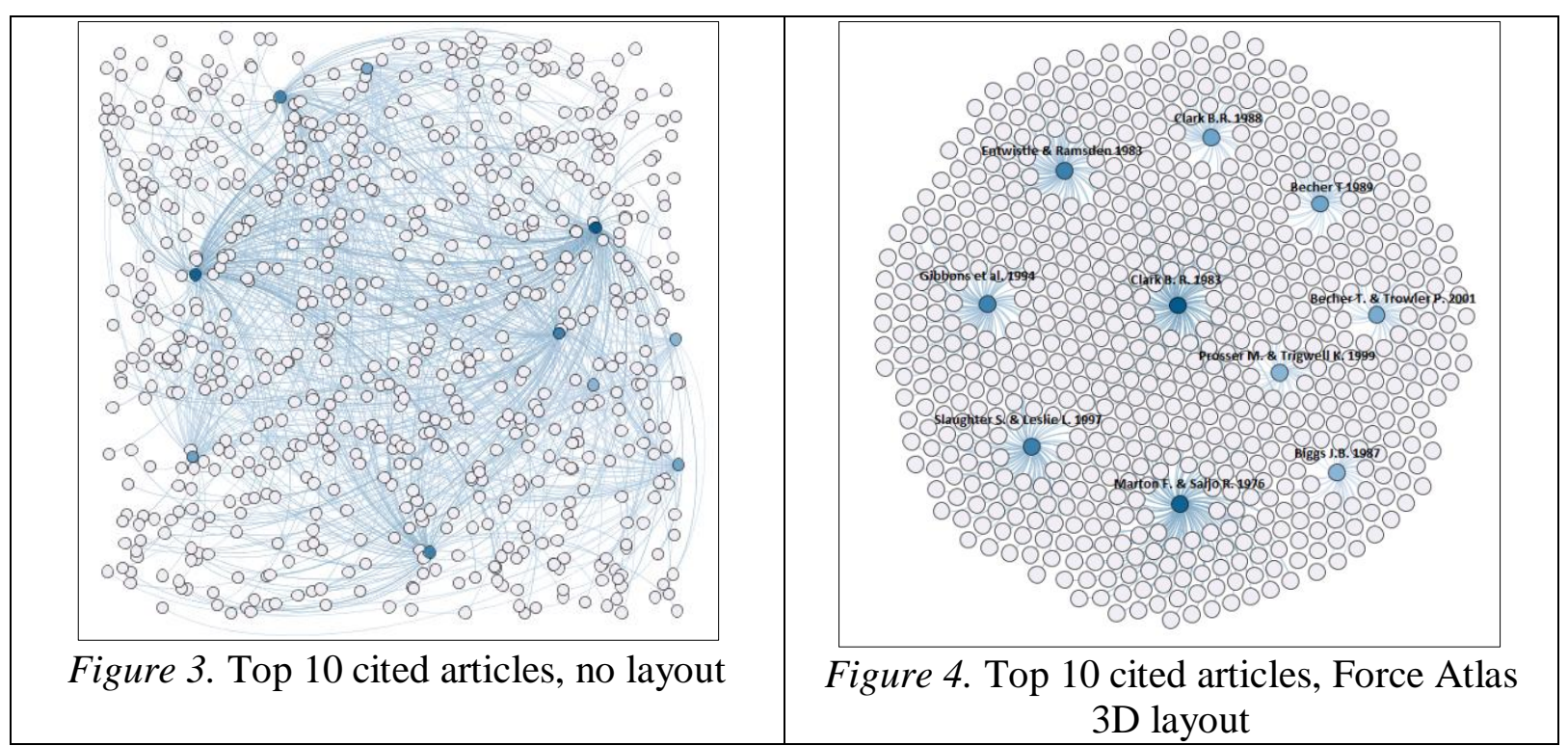


The 'degree' of a node indicates the number of edges to the node. For example, Clark's article shows 109 edges, Marton and Saljo's 103, and so on (Table 6). Since the edges range from 1 to 109, the 'degree range' is also 1 to 109 which means that an article is cited from as low as one citation to as high as 109. As can be seen from Table 6, the top 10 authors have been cited from 45 (Biggs) to 109 times (Clark). Not making it into the top 10 means that an article had less than 45 citations. As expected, a significant number of articles in the database only have one citation (i.e., many articles were only cited once).

Figure 4 below provides another, quite different, visualisation of Clark's 1983 article and its connections to those papers that cited his article between 1972 and 2014. This representation uses a Circular layout view (Fig. 5). This shows the "spray" of citations-i.e., evidence of influence - emanating from Clark's article, and the relatively less prominent "spray" from the other top ten cited papers.

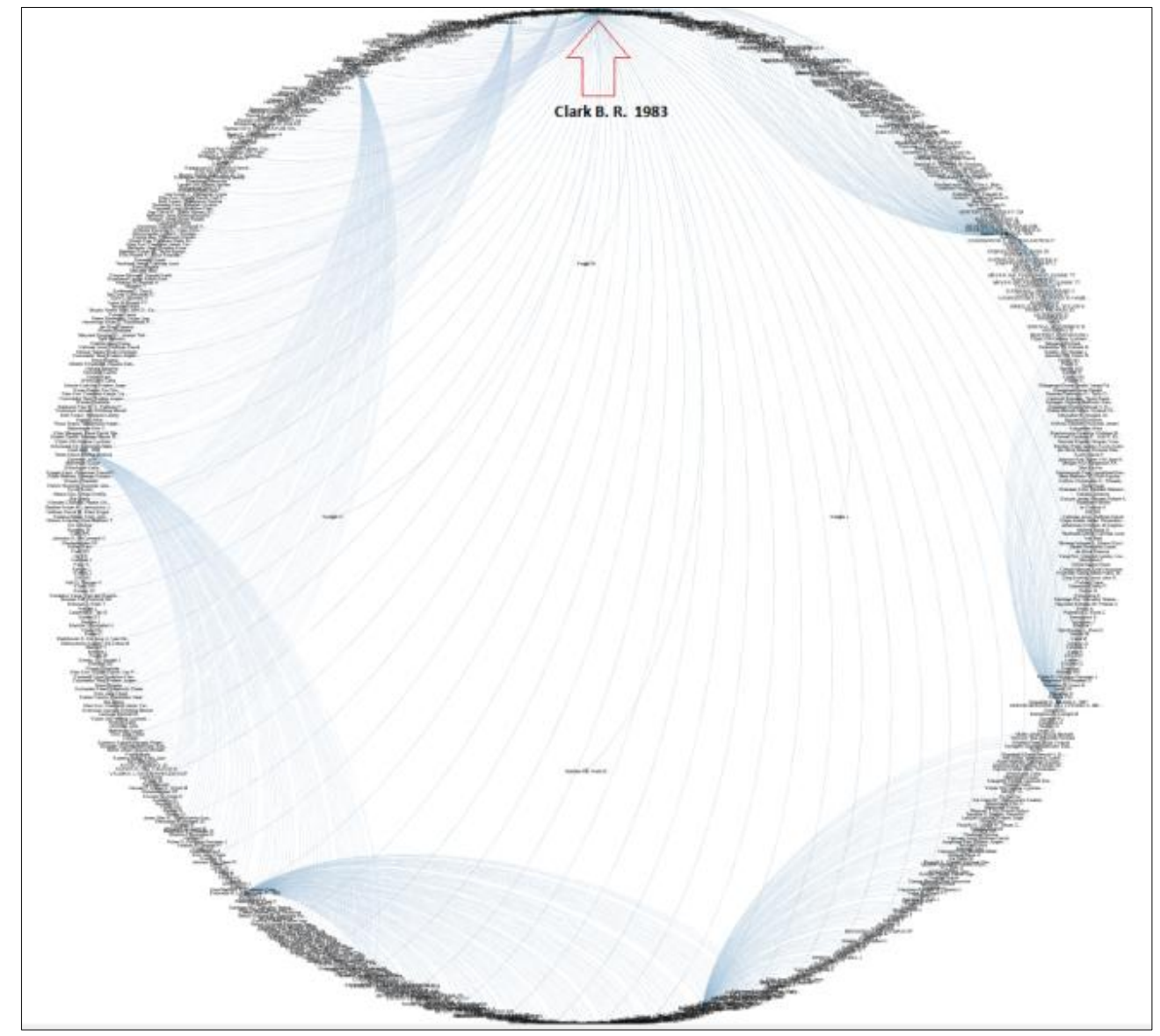

Figure 5. Clark's 1983 article and its connections, Circular layout

\section{Most cited authors}

Table 8 earlier showed the top 10 most cited authors (either as single or first author) from our own analysis using Excel®. Using the data from Table 8, a Gephi ${ }^{\mathrm{TM}}$ file was created containing 2,591 nodes and 2,581 edges. In this we use a Force Atlas 3D layout to provide a further way of representing the data. Figures 6 and 7 below show the associated Gephi ${ }^{\mathrm{TM}}$ 
diagrams associated with the top 10 most cited authors with varying degree of connections. Similar to the previous diagrams, the dots refer to the top 10 authors. The darker the colour, the more cited that author is. The distribution of connections is made clearer in Fig 7 with some of the "noise" removed and focussing only on the top 10 authors.

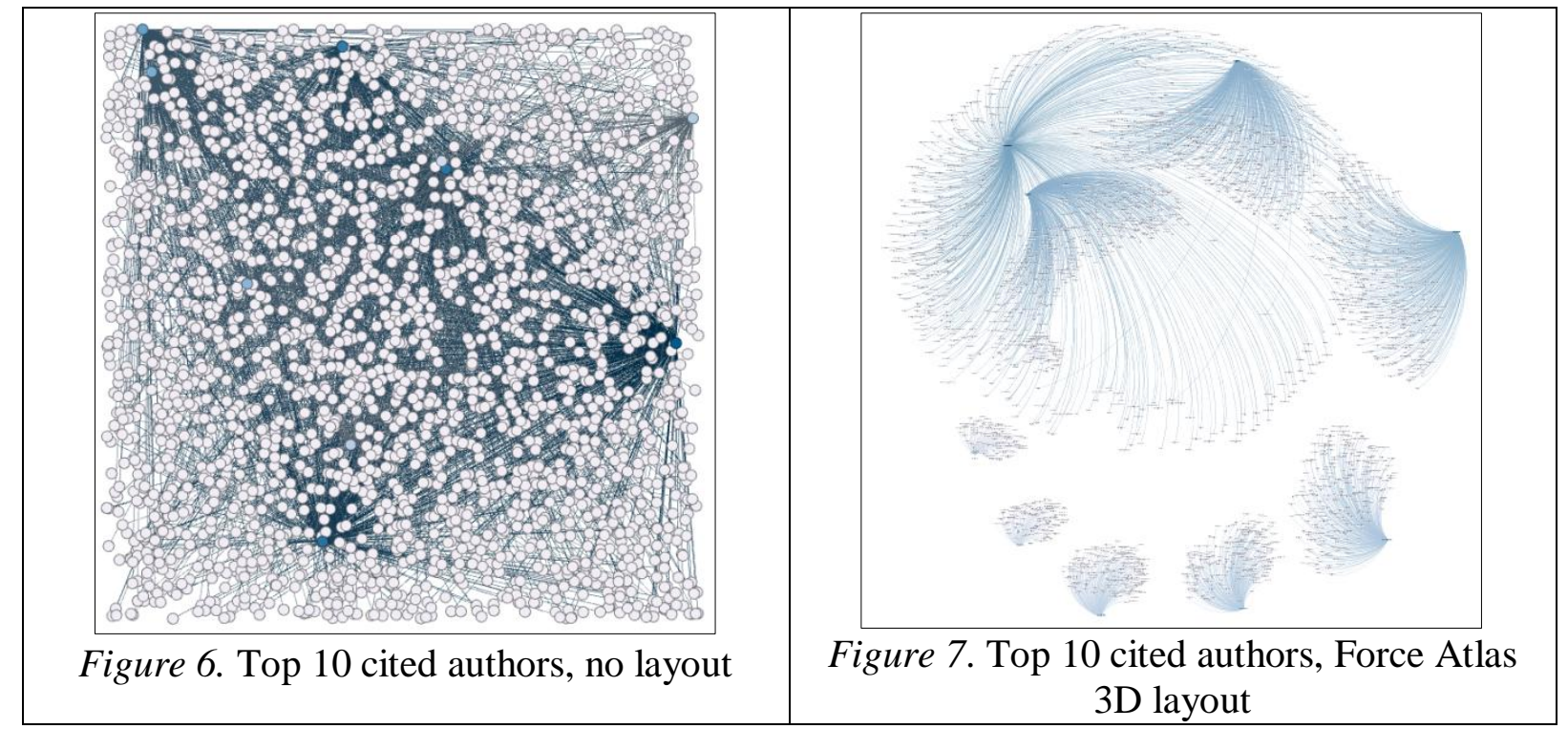

A close-up view of Figure 7 is shown in Figure 8. Entwistle has the most number of edges/connections/citations (472). This is followed by Clark, Marton and Biggs.

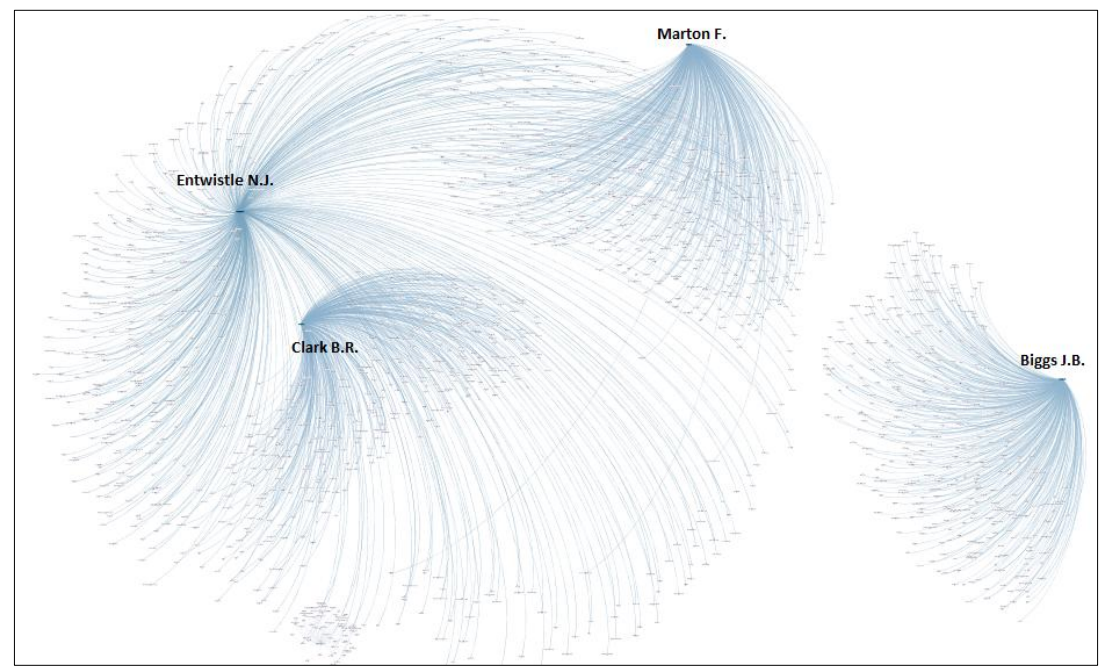

Figure 8. Detail showing Entwistle, Clark, Marton and Biggs' connections, Force Atlas 3D layout

Yet another representation of the data can be given using YifanHu layout. Figure 9 below shows the top 10 most cited authors with varying degrees of connectedness. The most cited author, Entwistle, is reflected with a larger circle, the darkest colour, and the greatest "tail" of citations (see Fig. 9). 


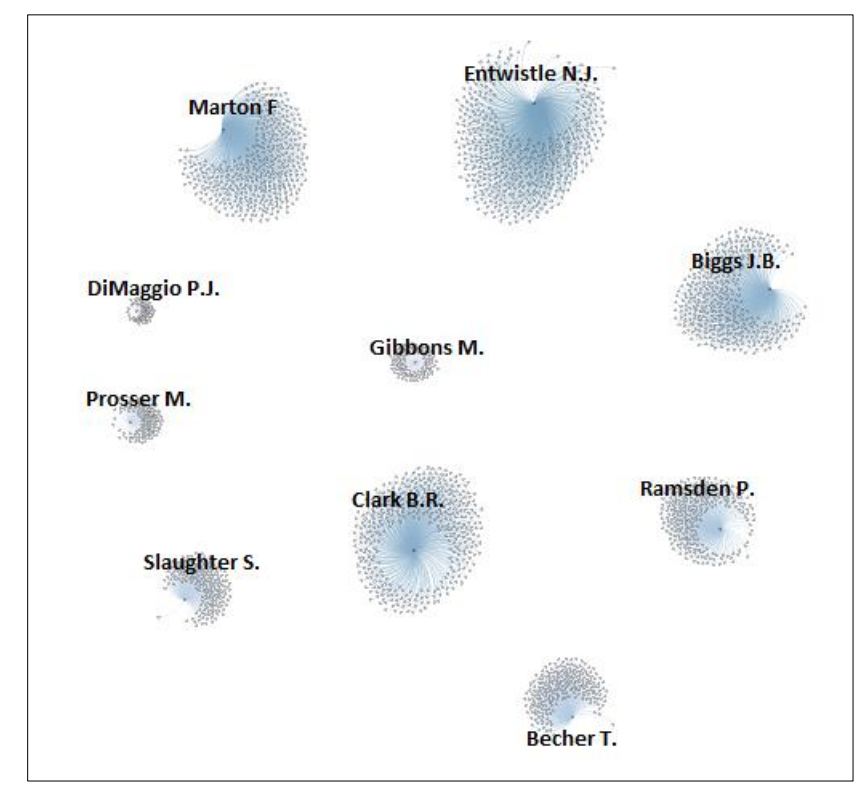

Figure 9. Top 10 most cited authors, YifanHu Multilevel layout

\section{Discussion}

How does all this compare to Macfarlane's "archipelago" and Tight's "cluster of relationships" with which we began this paper?

Following Macfarlane's tongue-in-cheek geographical analogy in his paper on citation analysis mentioned earlier (Macfarlane, 2012), these shoals can be thought of as "islands of influence" - though significantly, in our paper (unlike Macfarlane's) we have seen that these "islands" have an empirical basis. The diagrams we have presented, grounded as they are on the data from the history of the journal, really do demonstrate the "geography" of the discipline of Higher Education (see Figs 8 and 9 above).

A further form of representation, the YifanHu Multilevel layout (Figure 10), helps to illustrate the same geography as Figures 8 and 9 but with a closer resolution, showing the terrain of citations in Higher Education, and the contours, or peaks and troughs, of scholarly networks. These diagrams can be taken to represent the "world" of the journal, as it were, since 1972, at least in terms of the top 10 most cited authors.

Note two things about Figure 10:

- The various cases from the raw data (i.e., caps, no caps) have been counted all to their respective author IDs (i.e., ENTWHISTLE, Entwistl, Entwhistle, etc., all were coded to Entwistle).

- The diagram is necessarily much larger than figures 8 and 9 as it represents the full extent of the geographies of influence in diagrammatic form (i.e., not merely the top10). To assist comprehension, we have placed circles over the top-10 most cited authors-Entwistle, Clark, Marton, Biggs, Ramsden, Becher, Slaughter, Prosser, Gibbons and DiMaggio - to indicate their respective extent of influence. The most cited author, Entwistle, for example, has 472 authors who cited him within his circle. 

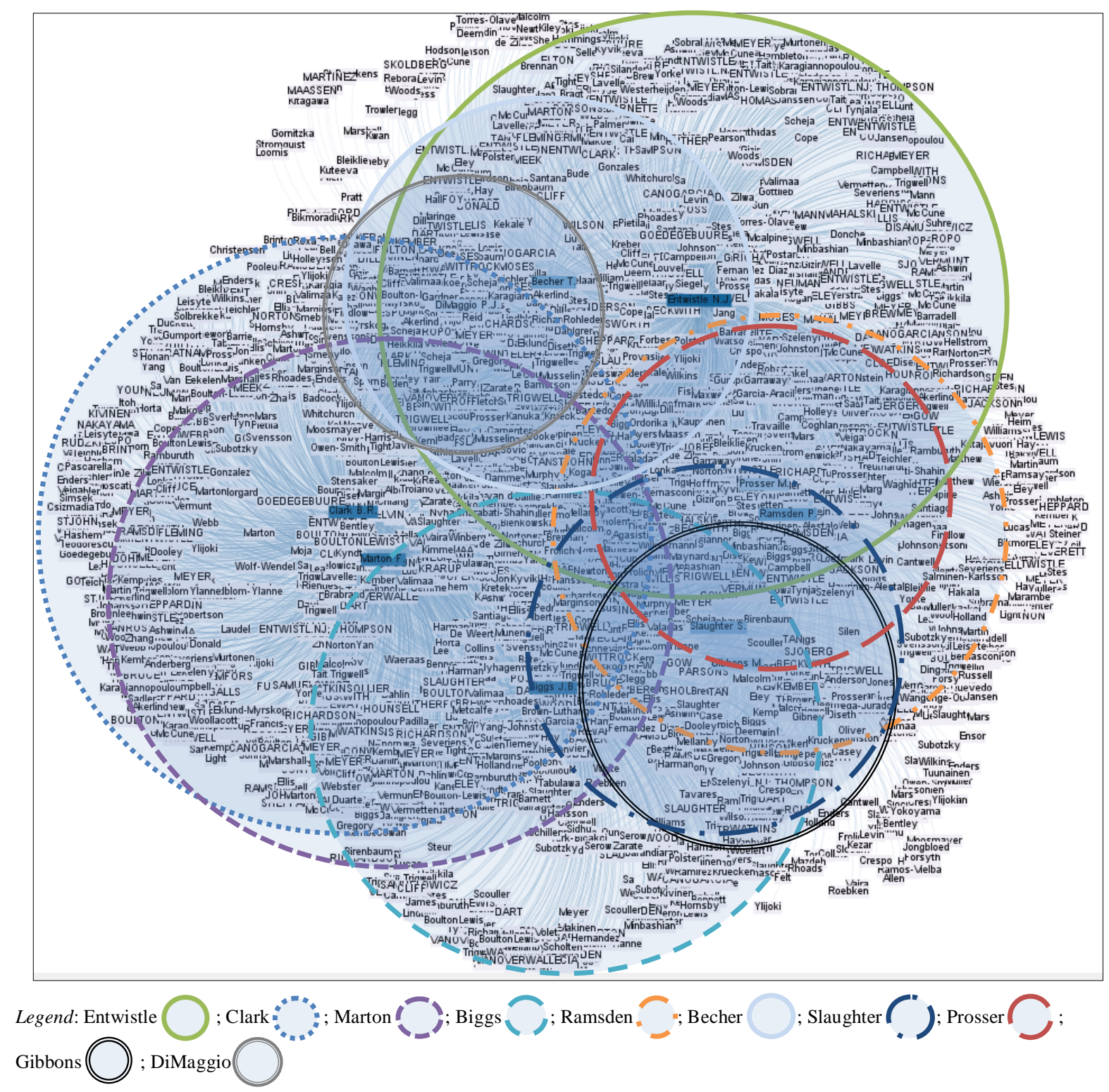

Figure 10. Top 10 most cited authors, YifanHu layout

One of the research questions of this paper was to investigate whether there were similarities and differences in the 'most cited' authors, and also to assess whether any discernible geographical bias existed amongst publications in international higher education journals published in different regions. Other questions raised related to which authors in the field feature pre-eminently in terms of citations, and which transcend national and international borders? We can now definitively answer these questions.

In the literature review we outlined data from five previous studies, including our analysis of the entire publication history of SHE. We wanted to investigate this further with another northern hemisphere journal, this time based in Europe. We decided on Higher Education for this purpose. Would the data from the entire history of the journal reveal similar trends? We can now draw some conclusions about the data. 
First: Our investigation of the journal $H E$ similarly indicates a near-identical list of top-five 'most cited' authors as our earlier analysis of SHE (see Table 10). It also reveals considerable overlap with the lists of Kandlbinder and Tight (Ramsden, Biggs, and Clark were noted by Tight; Entwistle, Ramsden, Biggs and Marton were noted by Kandlbinder).

Second: It seems clear from this that: a) there are regional biases comparing US journals to UK/European/Australasian journals (US journals do tend to preference US-based authors); and b) the 'top five' most cited authors in UK/European/Australasian journals is virtually identical. This is clearly not the case with American journals (Table 10). The "Atlantic divide" in higher education journals, it seems, incorporates the Antipodes with the UK and Europe, and never the twain shall meet. It seems that higher education research really does operate in two different geographic domains, at least in terms of the citation networks.

Third: In the case of Higher Education we have established with some certainty, the most published author (Meyer), the most cited article (Clark), and the most cited author (Entwistle). We have also established that these authors do not cross national boundaries to the extent they feature in US journals. By contrast, among the Anglo-European and Australian hemispheres there is much in the way of cross-border pollination. However, this can equally be said of the most cited authors from US journals-none of them feature in Anglo-European and Australian journals. Why this might be the case is a question we cannot presently answer.

Table 10

US, UK, Australia top authors from six various analyses

\begin{tabular}{|c|c|c|c|c|c|c|}
\hline & \multicolumn{2}{|c|}{ US } & UK & \multicolumn{3}{|c|}{ Australian } \\
\hline $\begin{array}{c}\text { Budd } \\
(1990)\end{array}$ & $\begin{array}{c}\text { Budd and } \\
\text { Magnuson } \\
(2010)\end{array}$ & $\begin{array}{c}\text { Tight } \\
(2008)\end{array}$ & $\begin{array}{c}\text { Kandlbinder } \\
(2012)\end{array}$ & $\begin{array}{c}\text { Calma and } \\
\text { Davies } \\
(2015)\end{array}$ & $\begin{array}{c}\text { Calma and } \\
\text { Davies } \\
\text { (current) }\end{array}$ \\
\hline 1 & Astin & Astin & Clark & Biggs & Entwistle & Entwistle \\
\hline 2 & Pascarella & Pascarella & Ramsden & Marton & Marton & Clark \\
\hline 3 & Centra & Tinto & Becher & Entwistle & Ramsden & Marton \\
\hline 4 & Baldridge & Kuh & Biggs & Ramsden & Biggs & Biggs \\
\hline 5 & Feldman & Cabrara & Boud & Becher & Becher & Ramsden \\
\hline
\end{tabular}

\section{Conclusion}

On the basis of available data drawn from 42 years of the journal, Higher Education, can indeed lay claim to be 'recognised as [one of] the leading journal of higher education studies' ('About this journal', 2015). Triangulated data is a clear indicator of this. An analysis of the journal citation metrics reveals that its leading authors are entirely consistent with-although not precisely the same as - other leading journals Studies in Higher Education (Calma \& Davies, 2015) and Higher Education Research and Development (Kandlbinder, 2012) as well as published studies on citation analysis elsewhere (Tight, 2008). The journals' proximate "impact factors" are (respectively) 1.222 (SHE), 1.207 (HE) 0.911 (HERD) yields further evidence of their relative importance. It remains for us to conduct a similar study of a key US 
journal, using the Gephi ${ }^{\mathrm{TM}}$ tool, and establish the extent of similarities and differences with existing studies. We are presently engaged in this task.

\section{Reference List}

'About this journal' (2015) Higher Education: The International Journal of Higher Education Springer.http://www.springer.com/education+\%26+language/higher+education/journa $1 / 10734$

Anglin, G. J., \& Towers, R. L. (1991). Citation Networks of Selected Instructional Design and Technology Journals, 1985-1990. ED334970. http://eric.ed.gov/?id=ED334970.

Barberán, A., Bates, S. T., Casamayor, E. O., \& Fierer, N. (2012). Using network analysis to explore co-occurrence patterns in soil microbial communities. ISME Journal: Multidisciplinary Journal of Microbial Ecology, 6(2), 343-351.

Becher, T., \& Trowler, P. (2001). Academic tribes and territories: Intellectual enquiry and the culture of disciplines (2nd ed.). Buckingham: The Society for Research into Higher Education \& Open University Press

Bodenhorn, H., (2003), Economic Scholarship at Elite Liberal Arts Colleges: A Citation Analysis with Rankings. The Journal of Economics Education, 34(4), 341-359.

Bornmann, L., Leydesdorff, L., \& Marx, W. (2007). Citation environment of Angewandte Chemie. CHIMIA, 61(3), 104-109.

Bruner, M. W., Erickson, K., Wilson, B., \& Côté, J. (2010). An appraisal of athlete development models through citation network analysis. Psychology of Sport \& Exercise, 11(2), 133-139.

Brughmans, T., (2012), Connecting the Dots: Toward Archeological Networks Analysis. Oxford Journal of Archaeology, 29(3), 277-303.

Budd, J. M. (1990). Higher Education Literature: Characteristics of Citation Patterns. Journal of Higher Education, 61(1), 84-97.

Budd, J. M., \& Magnuson, L. (2010). Higher Education Literature Revisited: Citation Patterns Examined. Research in Higher Education, 51(3), 294-304.

Calma, A., \& Davies, W. M. (2015). Studies in Higher Education 1976-2013: a retrospective using citation network analysis. Studies in Higher Education, 40(1), 4-21.

Cho, Y., \& Park, S. (2012). Using Citation Network Analysis in Educational Technology. Educational Technology, 52(3), 38-42.

Healy, K. (2013). A Co-citation network for Philosophy. http://kieranhealy.org/blog/archives/2013/06/18/a-co-citation-network-forphilosophy/.

Howard, J. (2011). Citation by Citation, New Maps Chart Hot Research and Scholarship's Hidden Terrain. (cover story). Chronicle of Higher Education, 58(4), A1.

Huisman, J. (2008). Higher Education Policy: The Evolution of a Journal. Higher Education Policy, 21(2), 265-274.Kandlbinder, P. (2012). Recognition and Influence: The Evolution of Higher Education Research and Development. Higher Education Research and Development, 31(1), 5-13.

Klein, W. C. \& Bloom, M. (1992). Studies of scholarly productivity in social work using citation analysis. Journal of Social Work Education, 28, 291-299.

Leydesdorff, L. (2007). Visualization of the citation impact environments of scientific journals: An online mapping exercise. Journal of the American Society for Information Science \& Technology, 58(1), 25-38. 
Macfarlane, B., (2012), The higher education research Archipeligo. Higher Education Research and Development, 31(1), 129-131.

Moore, S., Shiell, A., Hawe, P., \& Haines, V. A. (2005). The Privileging of Communitarian Ideas: Citation Practices and the Translation of Social Capital Into Public Health Research. American Journal of Public Health, 95(8), 1330-1337.

Nightingale, J. M., and Marshall, G., (2012). Citation Analysis as a Measure of Article Quality, Journal Influence and Individual Researcher Performance. Radiography, 18, 60-67.

Rangeon, S., Gilbert, W., \& Bruner, M. (2011). Mapping the World of Coaching Science: A Citation Network Analysis. Research Quarterly for Exercise and Sport 82(1), A50A51.

Ross, A. M. (1992). Two decades of higher education. Higher Education, 23(2), 99-112.

Tight, M. (2014). Working in separate silos? What citation patterns reveal about higher education research internationally. Higher Education, 68(3), 379-395.

Tight, M. (2008). Higher education research as tribe, territory and/or community: a cocitation analysis. Higher Education, 55(5), 593-605.

Thyer, B. A., and Bentley, K. J. (1986), Academic Affiliations of Social Work Authors: A Citation Analysis of Six Major Journals. Journal of Social Work Education, 22(1) 6773.

Westbury, I., (1980), The Impact of the Journal of Curriculum Studies: A Citation Analysis. Curriculum Studies, 12(2) 149-156.

Xian, H., \& Madhavan, K. (2013). Building On and Honoring Forty Years of PBL Scholarship from Howard Barrows: A Scientometric, Large-Scale Data, and Visualization-based Analysis.Interdisciplinary Journal of Problem-Based Learning, $7(1)$. 